\title{
Research methods of V/F control for matrix converter use direct space vector modulation
}

\author{
Bogdan Vasilev, Le Van Tung \\ Department of electric power and electromechanics, Saint-Petersburg Mining University, Russian Federation
}

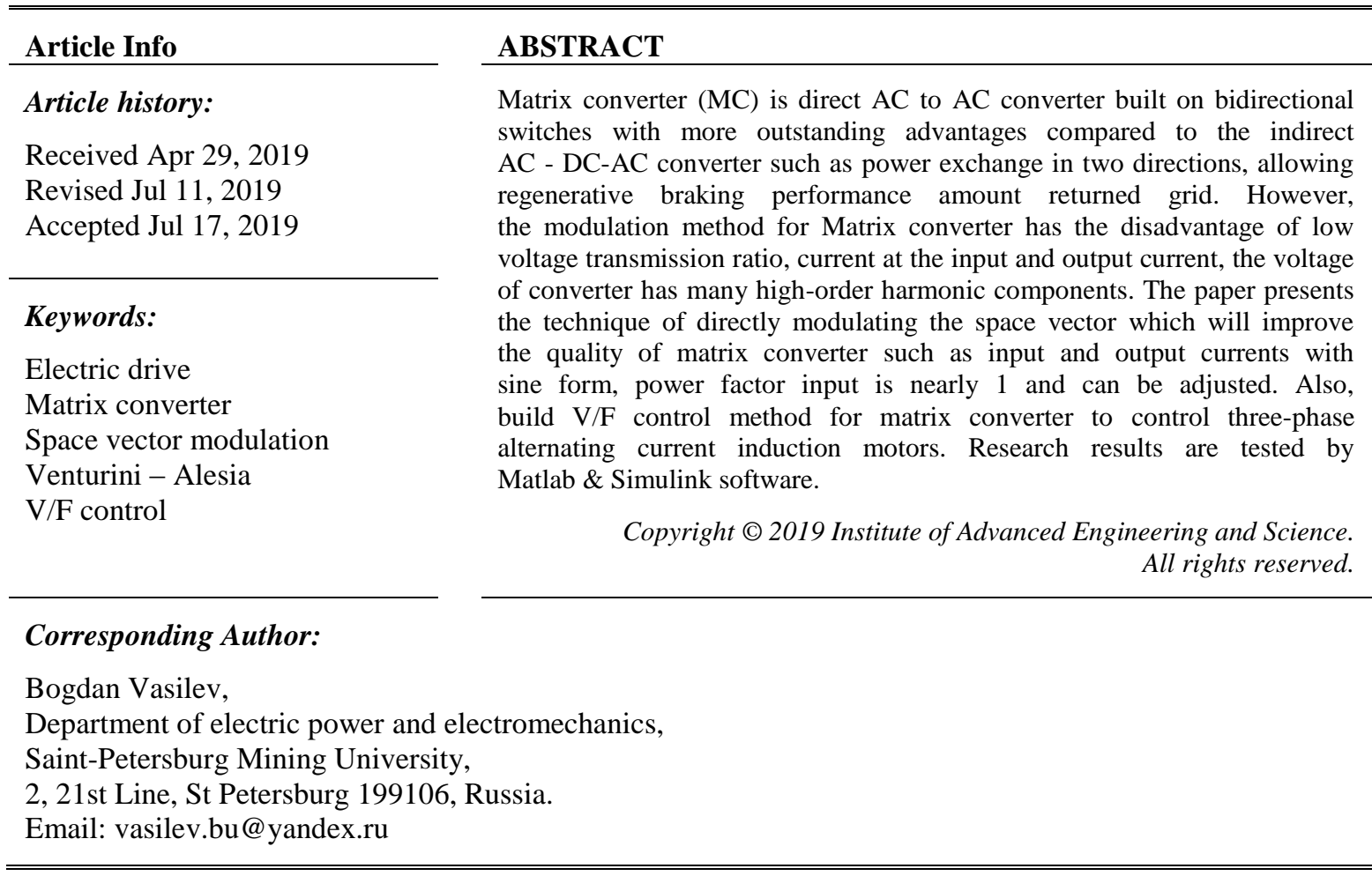

\section{INTRODUCTION}

The indirect converter (AC-DC-AC) is commonly used in practice today, with the advantages of: using a switch in one direction, simple modulation method, easy manufacture of inverter, low cost. However, they have a low power factor $\cos \varphi$, causing high-order harmonics to the grid voltage; no sinusoidal input current; when working with the load regenerative braking, the energy dissipation on the braking resistor that cannot be returned to the grid, will waste energy. At the same time, the structure of the converter becomes bulky when there is a braking resistor and DC-link component, which requires a Clamp protection circuit [1-5].

Matrix Converter is a direct converter which has many advantages over the indirect converter such as high performance, energy interchange in both directions, sinusoidal input current and output voltage [6-10]. Currently, MC is being researched on the fabrication technology of bidirectional switches (BDS) and methods of controlling switches. The main problem is that the modulation method in the MC is more complicated than the indirect converter due to the width of the square pulse when modulation depends only on the voltage value at the time of sampling signals, because of the input of converter is DC power but in $\mathrm{MC}$ the width of the square pulse when modulation depends on the value of AC voltage input at immediately [11-15].

Modulation methods for the MC converter must ensure that the two basic rules are observed: avoid short circuit at the converter input voltage source to avoid generating over current, and never interrupt the current source (load side) to avoid overvoltage on the switch. Currently, the modulation methods for MC such as 3M (min, medium, max), Venturini - Alesia are rarely used because they have complex calculation methods, which need more trigonometry calculations to create control signals. Input voltage values also need 
measures and continuous updates that require high accuracy [16-20]. Figure 1 shows the diagram of matrix converter while the diagram of bidirectional switches is shown in Figure 2.

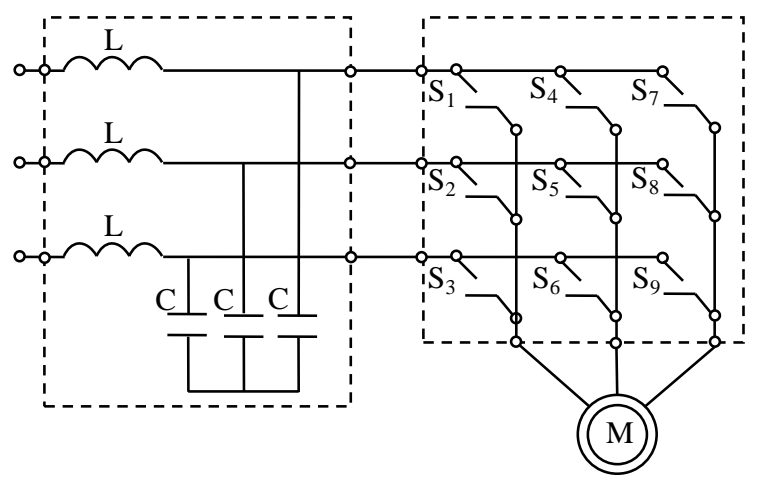

Figure 1. Diagram of matrix converter
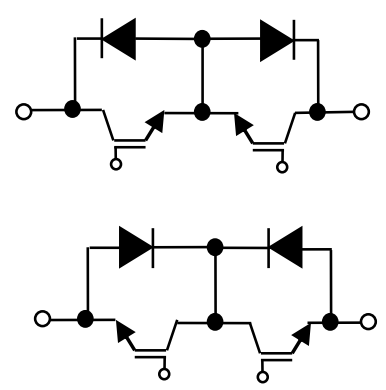

Figure 2. Diagram of bidirectional switches

The 3M method has a simple calculation but the effectiveness of this method depends on the accuracy of the value measured immediately, which makes it difficult for practical applications. Because these methods have many disadvantages, now scientists are continuing to research and develop the modulation space vector algorithm for matrix converter.

The modulation space vector method (SVM) has an easy advantage of programming on microprocessors, requiring less computation, using a complex numbers calculator to represent the vector of all electrical quantities and the switching states on the diagram. This helps in obtaining general results for many cases [21-25].

SVM modulation rules are divided into 2 main methods:

- Direct Space Vector Modulation (DSVM)

- Indirect Space Vector Modulation (ISVM)

The modulation method of DSVM does not need to separate the structure of the matrix converter into two parts: rectifier and inverter. Therefore, the calculation will be convenient and simple.

\section{DIRECT SPACE VECTOR MODULATION METHOD FOR MATRIX CONVERTER}

\subsection{Identify space vectors}

The structure diagram of an MC is shown in Figure 1. In this scheme the output voltage is formed from the input voltage, the output current is determined by the load. The input current is calculated from the output current and its value will be minimal if the phase shift angle of the current compared to the voltage is zero. In vector space, a system of three phase output voltages is represented by a rotating vector on the coordinate system $0 \alpha \beta[8]$.

$$
u_{0}=\frac{2}{3}\left(U_{A B}+e^{\frac{2 j \pi}{3}} U_{B C}+e^{\frac{4 j \pi}{3}} U_{C A}\right)
$$

If the system has the desired output voltage in three symmetrical phases, it is possible to represent them as follows:

$$
\begin{aligned}
& u_{A B}=U_{0} \cos \left(\omega_{0} t+\frac{\pi}{6}\right) \\
& u_{B C}=U_{0} \cos \left(\omega_{0} t+\frac{\pi}{6}-\frac{2 \pi}{3}\right) \\
& u_{C A}=U_{0} \cos \left(\omega_{0} t+\frac{\pi}{6}+\frac{2 \pi}{3}\right)
\end{aligned}
$$

Here $U_{o}, \omega_{0}$ is the amplitude and angular velocity value of the desired output voltage. The value of $\pi / 6$ represents the phase shift angle between line voltage and phase voltage. 
The output voltage vector is also presented as follows:

$$
\bar{u}=u(t) e^{j\left(\omega_{0} t\right)}=U_{0} e^{j \frac{\pi}{6}} e^{j\left(\omega_{0} t\right)}
$$

Similar to the voltage, the input current can be expressed as follows:

$$
\begin{aligned}
& i_{0}=\frac{2}{3}\left(i_{A}+e^{\frac{2 j \pi}{3}} i_{B}+e^{\frac{4 j \pi}{3}} i_{C}\right)=I_{0} e^{j\left(\omega_{0} t\right)} \\
& e_{i}=\frac{2}{3}\left(u_{a}+e^{\frac{2 j \pi}{3}} u_{b}+e^{\frac{4 j \pi}{3}} u_{c}\right)=E_{i} e^{j\left(\omega_{i} t\right)} \\
& i_{i}=\frac{2}{3}\left(i_{a}+e^{\frac{2 j \pi}{3}} i_{b}+e^{\frac{4 j \pi}{3}} i_{c}\right)=I_{i} e^{j\left(\omega_{i} t\right)}
\end{aligned}
$$

The modulation methods will be more convenient if the input line voltage vector is used as follows $[9,10]$ :

$$
u_{i}=\frac{2}{3}\left(U_{a b}+e^{\frac{2 j \pi}{3}} U_{b c}+e^{\frac{4 j \pi}{3}} U_{c a}\right)=U_{i}(t) e^{j\left(\omega_{i} t+\frac{\pi}{6}\right)}
$$

The control method of closing and opening the switch will generate the voltage, current and

\begin{tabular}{|c|c|c|c|c|c|c|c|c|c|c|c|c|c|}
\hline $\mathrm{N}_{0}$ & A & B & $\mathrm{C}$ & $\mathrm{u}_{\mathrm{AB}}$ & $\mathrm{u}_{\mathrm{BC}}$ & $\mathrm{u}_{\mathrm{CA}}$ & $\mathrm{U}_{\mathrm{o}}$ & $\theta_{\mathrm{o}}$ & $\mathrm{i}_{\mathrm{a}}$ & $\mathrm{i}_{\mathrm{b}}$ & $i_{c}$ & $\mathrm{I}_{\mathrm{i}}$ & $\alpha_{i}$ \\
\hline $1+$ & A & $\mathrm{b}$ & $\mathrm{b}$ & $\mathrm{u}_{\mathrm{ab}}$ & 0 & $-\mathrm{u}_{\mathrm{ab}}$ & $2 / \sqrt{3} u_{a b}$ & $\pi / 6$ & $i_{A}$ & $-\mathrm{i}_{\mathrm{A}}$ & 0 & $2 / \sqrt{3} i_{A}$ & $-\pi / 6$ \\
\hline $1-$ & B & $\mathrm{a}$ & $\mathrm{a}$ & $-\mathrm{u}_{\mathrm{ab}}$ & 0 & $\mathrm{u}_{\mathrm{ab}}$ & $2 / \sqrt{3} u_{a b}$ & $-5 \pi / 6$ & $-i_{A}$ & $i_{A}$ & 0 & $2 / \sqrt{3} i_{A}$ & $5 \pi / 6$ \\
\hline $2+$ & B & $\mathrm{c}$ & $\mathrm{c}$ & $\mathrm{u}_{\mathrm{bc}}$ & 0 & $-\mathrm{u}_{\mathrm{bc}}$ & $2 / \sqrt{3} \mathrm{u}_{\mathrm{bc}}$ & $\pi / 6$ & 0 & $\mathrm{i}_{\mathrm{A}}$ & $-\mathrm{i}_{\mathrm{A}}$ & $2 / \sqrt{3} i_{A}$ & $\pi / 2$ \\
\hline $2-$ & $\mathrm{C}$ & b & $\mathrm{b}$ & $-\mathrm{u}_{\mathrm{bc}}$ & 0 & $\mathrm{u}_{\mathrm{bc}}$ & $2 / \sqrt{3} u_{b c}$ & $-5 \pi / 6$ & 0 & $-i_{A}$ & $\mathrm{i}_{\mathrm{A}}$ & $2 / \sqrt{3} \mathrm{i}_{\mathrm{A}}$ & $-\pi / 2$ \\
\hline $3+$ & $\mathrm{C}$ & $\mathrm{a}$ & $\mathrm{a}$ & $\mathrm{u}_{\mathrm{ca}}$ & 0 & $-\mathrm{u}_{\mathrm{ca}}$ & $2 / \sqrt{3} \mathrm{u}_{\mathrm{ca}}$ & $\pi / 6$ & $-\mathrm{i}_{\mathrm{A}}$ & 0 & $i_{A}$ & $2 / \sqrt{3} i_{A}$ & $-5 \pi / 6$ \\
\hline $3-$ & $\mathrm{a}$ & $\mathrm{c}$ & $\mathrm{c}$ & $-\mathrm{u}_{\mathrm{ca}}$ & 0 & $\mathrm{u}_{\mathrm{ca}}$ & $2 / \sqrt{3} \mathrm{u}_{\mathrm{ca}}$ & $-5 \pi / 6$ & $\mathrm{i}_{\mathrm{A}}$ & 0 & $-i_{A}$ & $2 / \sqrt{3} \mathrm{i}_{\mathrm{A}}$ & $\pi / 6$ \\
\hline $4+$ & $\mathrm{b}$ & $\mathrm{a}$ & $\mathrm{b}$ & $-\mathrm{u}_{\mathrm{ab}}$ & $\mathrm{u}_{\mathrm{ab}}$ & 0 & $2 / \sqrt{3} \mathrm{u}_{\mathrm{ab}}$ & $5 \pi / 6$ & $i_{B}$ & $-i_{B}$ & 0 & $2 / \sqrt{3} i_{B}$ & $-\pi / 6$ \\
\hline 4- & $\mathrm{a}$ & $\mathrm{b}$ & $\mathrm{a}$ & $\mathrm{u}_{\mathrm{ab}}$ & $-u_{a b}$ & 0 & $2 / \sqrt{3} \mathrm{u}_{\mathrm{ab}}$ & $-\pi / 6$ & $-i_{B}$ & $\mathrm{i}_{\mathrm{B}}$ & 0 & $2 / \sqrt{3} \mathrm{i}_{\mathrm{B}}$ & $5 \pi / 6$ \\
\hline $5+$ & $\mathrm{c}$ & b & $\mathrm{c}$ & $-\mathrm{u}_{\mathrm{bc}}$ & $\mathrm{u}_{\mathrm{bc}}$ & 0 & $2 / \sqrt{3} u_{b c}$ & $5 \pi / 6$ & 0 & $\mathrm{i}_{\mathrm{B}}$ & $-\mathrm{i}_{\mathrm{B}}$ & $2 / \sqrt{3} \mathrm{i}_{\mathrm{B}}$ & $\pi / 2$ \\
\hline 5- & $\mathrm{b}$ & $\mathrm{c}$ & $\mathrm{b}$ & $\mathrm{u}_{\mathrm{bc}}$ & $-\mathrm{u}_{\mathrm{bc}}$ & 0 & $2 / \sqrt{3} \mathrm{u}_{\mathrm{bc}}$ & $-\pi / 6$ & 0 & $-\mathrm{i}_{\mathrm{B}}$ & $i_{B}$ & $2 / \sqrt{3} \mathrm{i}_{\mathrm{B}}$ & $-\pi / 2$ \\
\hline $6+$ & $\mathrm{a}$ & $\mathrm{c}$ & $\mathrm{a}$ & $-\mathrm{u}_{\mathrm{ca}}$ & $\mathrm{u}_{\mathrm{ca}}$ & 0 & $2 / \sqrt{3} \mathrm{u}_{\mathrm{ca}}$ & $5 \pi / 6$ & $-i_{B}$ & 0 & $i_{B}$ & $2 / \sqrt{3} \mathrm{i}_{\mathrm{B}}$ & $-5 \pi / 6$ \\
\hline 6- & $\mathrm{c}$ & $\mathrm{a}$ & $\mathrm{c}$ & $\mathrm{u}_{\mathrm{ca}}$ & $-\mathrm{u}_{\mathrm{ca}}$ & 0 & $2 / \sqrt{3} \mathrm{u}_{\mathrm{ca}}$ & $-\pi / 6$ & $\mathrm{i}_{\mathrm{B}}$ & 0 & $-i_{B}$ & $2 / \sqrt{3} \mathrm{i}_{\mathrm{B}}$ & $\pi / 6$ \\
\hline $7+$ & $\mathrm{b}$ & b & $\mathrm{a}$ & 0 & $-\mathrm{u}_{\mathrm{ab}}$ & $\mathrm{u}_{\mathrm{ab}}$ & $2 / \sqrt{3} u_{a b}$ & $-\pi / 2$ & $\mathrm{i}_{\mathrm{C}}$ & $-\mathrm{i}_{\mathrm{C}}$ & 0 & $2 / \sqrt{3} \mathrm{i}_{\mathrm{C}}$ & $-\pi / 6$ \\
\hline 7- & $\mathrm{a}$ & $\mathrm{a}$ & $\mathrm{b}$ & 0 & $\mathrm{u}_{\mathrm{ab}}$ & $-\mathrm{u}_{\mathrm{ab}}$ & $2 / \sqrt{3} \mathrm{u}_{\mathrm{ab}}$ & $\pi / 2$ & $-\mathrm{i}_{\mathrm{C}}$ & $\mathrm{i}_{\mathrm{C}}$ & 0 & $2 / \sqrt{3} i_{C}$ & $5 \pi / 6$ \\
\hline $8+$ & $\mathrm{c}$ & $\mathrm{c}$ & $\mathrm{b}$ & 0 & $-\mathrm{u}_{\mathrm{bc}}$ & $\mathrm{u}_{\mathrm{bc}}$ & $2 / \sqrt{3} u_{b c}$ & $-\pi / 2$ & 0 & $\mathrm{i}_{\mathrm{C}}$ & $-\mathrm{i}_{\mathrm{C}}$ & $2 / \sqrt{3} i_{C}$ & $\pi / 2$ \\
\hline 8- & $\mathrm{b}$ & $\mathrm{b}$ & $\mathrm{c}$ & 0 & $\mathrm{u}_{\mathrm{bc}}$ & $-\mathrm{u}_{\mathrm{bc}}$ & $2 / \sqrt{3} u_{b c}$ & $\pi / 2$ & 0 & $-\mathrm{i}_{\mathrm{C}}$ & $\mathrm{i}_{\mathrm{C}}$ & $2 / \sqrt{3} i_{C}$ & $-\pi / 2$ \\
\hline $9+$ & $\mathrm{a}$ & $\mathrm{a}$ & $\mathrm{c}$ & 0 & $-\mathrm{u}_{\mathrm{ca}}$ & $\mathrm{u}_{\mathrm{ca}}$ & $2 / \sqrt{3} \mathrm{u}_{\mathrm{ca}}$ & $-\pi / 2$ & $-\mathrm{i}_{\mathrm{C}}$ & 0 & $\mathrm{i}_{\mathrm{C}}$ & $2 / \sqrt{3} \mathrm{i}_{\mathrm{C}}$ & $-5 \pi / 6$ \\
\hline 9- & $\mathrm{c}$ & $\mathrm{c}$ & $\mathrm{a}$ & 0 & $\mathrm{u}_{\mathrm{ca}}$ & $-\mathrm{u}_{\mathrm{ca}}$ & $2 / \sqrt{3} \mathrm{u}_{\mathrm{ca}}$ & $\pi / 2$ & $\mathrm{i}_{\mathrm{C}}$ & 0 & $-i_{C}$ & $2 / \sqrt{3} i_{C}$ & $\pi / 6$ \\
\hline $0_{a}$ & $\mathrm{a}$ & $\mathrm{a}$ & $\mathrm{a}$ & 0 & 0 & 0 & & - & & & & & - \\
\hline $0_{\mathrm{b}}$ & b & $\mathrm{b}$ & $\mathrm{b}$ & 0 & 0 & 0 & & - & & & & & - \\
\hline \multirow[t]{7}{*}{$0_{c}$} & $\mathrm{c}$ & $\mathrm{c}$ & $\mathrm{c}$ & 0 & 0 & 0 & & - & & & & & - \\
\hline & $\mathrm{a}$ & $\mathrm{b}$ & $\mathrm{c}$ & & & & & & & & & & \\
\hline & b & $\mathrm{c}$ & $\mathrm{a}$ & & & & & & & & & & \\
\hline & $\mathrm{c}$ & $\mathrm{a}$ & $\mathrm{b}$ & & & & & & & & & & \\
\hline & $\mathrm{a}$ & $\mathrm{c}$ & $\mathrm{b}$ & & & & & & & & & & \\
\hline & b & $\mathrm{a}$ & $\mathrm{c}$ & & & & & & & & & & \\
\hline & c & $\mathrm{b}$ & $\mathrm{a}$ & & & & & & & & & & \\
\hline
\end{tabular}
phase angle values as shown in Table 1. In the 27 states shown in Table 1, the states in the last six rows are rotating vectors, the voltage will not be used in space vector modulation techniques because there is no way to use them.

Table 1. The value of the standard vectors corresponding to the output voltage and the input current

In the remaining 21 states in Table 1, the standard vectors determine the opening time of the switches in the branches of the matrix converter, thereby determining the angle of the rotating vector to calculate the output voltage. This is similar to the PWM modulation method but differs in the vector modulation method for MC when the amplitude of standard vectors changes over time. Based on the results in Table 1, space vectors are shown in Figure 3 and Figure 4. It indicates the corresponding switch combinations and divides the plane into six sectors [5]. 


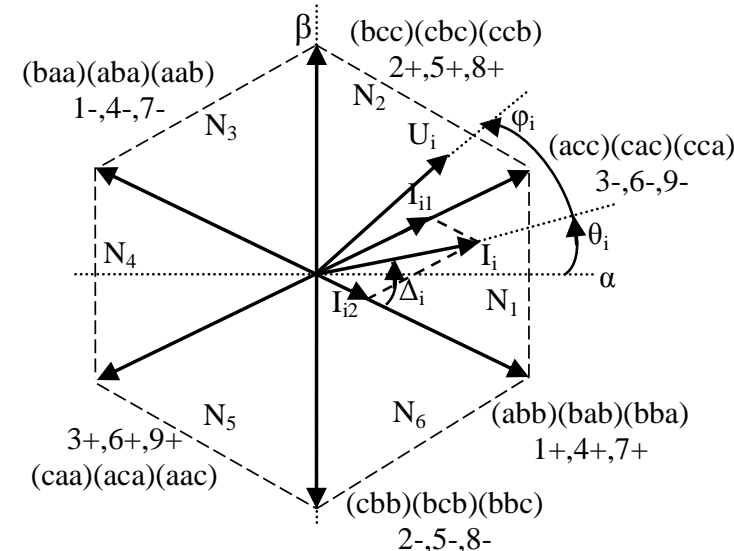

Figure 3. Input current vector

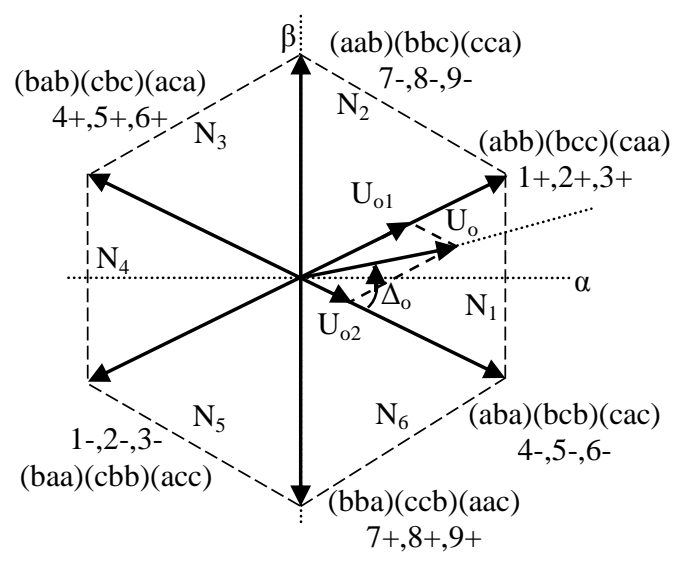

Figure 4. Output voltage vector

\subsection{Calculation of signal modulation coefficients}

If an output voltage vector is in any position on the coordinate system $0 \alpha \beta$, we can calculate this vector from two standard boundary vectors. On Figures 3 and 4 vector u0 is in the first corner (I) and is defined by the formula $\mathrm{u}_{0}=\mathrm{u}_{01}+\mathrm{u}_{02}$. Easily calculate the length of voltage vectors according to the trigonometric calculation as follows:

$$
\begin{aligned}
& U_{01}=\frac{U_{0}}{\sin \left(\frac{\pi}{3}\right)} \sin \Delta_{0}=U_{0} \sin \Delta_{0} \frac{2}{\sqrt{3}} \\
& U_{02}=\frac{U_{0}}{\sin \left(\frac{\pi}{3}\right)} \sin \left(\frac{\pi}{3}-\Delta_{0}\right)=U_{0} \sin \left(\frac{\pi}{3}-\Delta_{0}\right) \frac{2}{\sqrt{3}}
\end{aligned}
$$

Where $\Delta_{0}$ is the angle that determines the uo vector position in the coordinate plane.

Each of these component vectors is defined by two vectors that have the same orientation as the standard boundary vectors. The choice of some standard input voltage vector will depend on the position of the input current vector. With an input current vector having any position in the coordinate plane and can be calculated by the formula $\mathrm{i}_{\mathrm{i}}=\mathrm{i}_{\mathrm{i} 1}+\mathrm{i}_{\mathrm{i} 2}$, where $\mathrm{i}_{\mathrm{i} 1}, \mathrm{i}_{\mathrm{i} 2}$ are two standard boundary vectors. Each of these component vectors is modulated by two currents in the same direction.

By geometry calculations based on diagrams representing space vectors, there will be modulation coefficients $\mathrm{d} 1, \mathrm{~d} 2, \mathrm{~d} 3, \mathrm{~d} 4$ as follows:

$$
\begin{aligned}
& d_{1}=\frac{2\left|U_{0}\right|}{\sqrt{3}\left|U_{i}\right|} \frac{\sin \left(\Delta_{0}\right) \sin \left(\frac{\pi}{3}-\Delta_{i}\right)}{\cos \varphi_{i}} \\
& d_{2}=\frac{2\left|U_{0}\right|}{\sqrt{3}\left|U_{i}\right|} \frac{\sin \left(\Delta_{0}\right) \sin \left(\Delta_{i}\right)}{\cos \varphi_{i}} \\
& d_{3}=\frac{2\left|U_{0}\right|}{\sqrt{3}\left|U_{i}\right|} \frac{\sin \left(\frac{\pi}{3}-\Delta_{0}\right) \sin \left(\frac{\pi}{3}-\Delta_{i}\right)}{\cos \varphi_{i}} \\
& d_{4}=\frac{2\left|U_{0}\right|}{\sqrt{3}\left|U_{i}\right|} \frac{\sin \left(\frac{\pi}{3}-\Delta_{0}\right) \sin \left(\Delta_{i}\right)}{\cos \varphi_{i}}
\end{aligned}
$$

Modulation rules always guarantee expression:

$$
\left|d_{1}\right|+\left|d_{2}\right|+\left|d_{3}\right|+\left|d_{4}\right| \leq 1
$$

From expression (1) is derived the expression:

$$
\mathrm{U}_{0} \leq \mathrm{U}_{\mathrm{i}} \frac{\sqrt{3}}{2}\left|\cos \varphi_{\mathrm{i}}\right|
$$

Expression (2) shows that the maximum voltage transmission value of MC in DSVM method is $\sqrt{3} / 2=0,866$. This is the advantage of DSVM method compared to Venturini - Alesia and 3M method [3,4]. 
The absolute value of modulation factor $\mathrm{d}_{1}, \mathrm{~d}_{2}, \mathrm{~d}_{3}, \mathrm{~d}_{4}$ describes the present time of current vectors and voltage vectors used in sample cycle Ts. Table 2 lists the switch combinations and is chosen according to the position of the output voltage vector and the input current vector. The rule of modulation is that the vectors always ensure that only one double of BDS switches must close or open to reduce losses, when closing/opening, to the minimum level.

Table 2. Switching sequence of switches

\begin{tabular}{|c|c|c|c|c|c|c|c|}
\hline \multirow{2}{*}{\multicolumn{2}{|c|}{$\begin{array}{l}\text { Sector voltage and current } \\
\qquad N_{\mathrm{v}}-\mathrm{N}_{\mathrm{i}}\end{array}$}} & \multicolumn{5}{|c|}{ Combining current rectifier and inverter voltage circuit } & \multirow[t]{2}{*}{ Switching sequence } \\
\hline & & $\mathrm{d}_{4}$ & $\mathrm{~d}_{3}$ & $\mathrm{~d}_{2}$ & $\mathrm{~d}_{1}$ & $\mathrm{~d}_{0}$ & \\
\hline U1-I1 & U4-I4 & aca & aba & acc & $\mathrm{abb}$ & $\mathrm{ccc}$ & $\mathrm{d}_{1}-\mathrm{d}_{3}-\mathrm{d}_{4}-\mathrm{d}_{2}-\mathrm{d}_{0}-\mathrm{d}_{2}-\mathrm{d}_{4}-\mathrm{d}_{3}-\mathrm{d}_{1}$ \\
\hline U1-I2 & U4-I5 & bcb & aca & bcc & acc & bbb & $d_{3}-d_{1}-d_{2}-d_{4}-d_{0}-d_{4}-d_{2}-d_{1}-d_{3}$ \\
\hline U1-I3 & U4-I6 & bab & bcb & baa & bcc & aaa & $\mathrm{d}_{1}-\mathrm{d}_{3}-\mathrm{d}_{4}-\mathrm{d}_{2}-\mathrm{d}_{0}-\mathrm{d}_{2}-\mathrm{d}_{4}-\mathrm{d}_{3}-\mathrm{d}_{1}$ \\
\hline U1-I4 & U4-I1 & $\mathrm{cac}$ & $\mathrm{bab}$ & caa & baa & $\operatorname{ccc}$ & $\mathrm{d}_{3}-\mathrm{d}_{1}-\mathrm{d}_{2}-\mathrm{d}_{4}-\mathrm{d}_{0}-\mathrm{d}_{4}-\mathrm{d}_{2}-\mathrm{d}_{1}-\mathrm{d}_{3}$ \\
\hline U1-I5 & U4-I2 & $\mathrm{cbc}$ & cac & $\mathrm{cbb}$ & caa & bbb & $\mathrm{d}_{1}-\mathrm{d}_{3}-\mathrm{d}_{4}-\mathrm{d}_{2}-\mathrm{d}_{0}-\mathrm{d}_{2}-\mathrm{d}_{4}-\mathrm{d}_{3}-\mathrm{d}_{1}$ \\
\hline U1-I6 & U4-I3 & aba & $\mathrm{cbc}$ & $a b b$ & cbb & aaa & $\mathrm{d}_{3}-\mathrm{d}_{1}-\mathrm{d}_{2}-\mathrm{d}_{4}-\mathrm{d}_{0}-\mathrm{d}_{4}-\mathrm{d}_{2}-\mathrm{d}_{1}-\mathrm{d}_{3}$ \\
\hline U2-I1 & U5-I4 & acc & $a b b$ & aac & $a a b$ & $\mathrm{ccc}$ & $\mathrm{d}_{3}-\mathrm{d}_{1}-\mathrm{d}_{2}-\mathrm{d}_{4}-\mathrm{d}_{0}-\mathrm{d}_{4}-\mathrm{d}_{2}-\mathrm{d}_{1}-\mathrm{d}_{3}$ \\
\hline $\mathrm{U} 2-\mathrm{I} 2$ & U5-I5 & bcc & acc & bbc & aac & bbb & $\mathrm{d}_{1}-\mathrm{d}_{3}-\mathrm{d}_{4}-\mathrm{d}_{2}-\mathrm{d}_{0}-\mathrm{d}_{2}-\mathrm{d}_{4}-\mathrm{d}_{3}-\mathrm{d}_{1}$ \\
\hline $\mathrm{U} 2-\mathrm{I} 3$ & U5-I6 & baa & bcc & bba & bbc & aaa & $\mathrm{d}_{3}-\mathrm{d}_{1}-\mathrm{d}_{2}-\mathrm{d}_{4}-\mathrm{d}_{0}-\mathrm{d}_{4}-\mathrm{d}_{2}-\mathrm{d}_{1}-\mathrm{d}_{3}$ \\
\hline U2-I4 & U5-I1 & caa & baa & cca & bba & $\mathrm{ccc}$ & $\mathrm{d}_{1}-\mathrm{d}_{3}-\mathrm{d}_{4}-\mathrm{d}_{2}-\mathrm{d}_{0}-\mathrm{d}_{2}-\mathrm{d}_{4}-\mathrm{d}_{3}-\mathrm{d}_{1}$ \\
\hline U2-I5 & U5-I2 & $\mathrm{cbb}$ & caa & $\mathrm{ccb}$ & cca & bbb & $\mathrm{d}_{3}-\mathrm{d}_{1}-\mathrm{d}_{2}-\mathrm{d}_{4}-\mathrm{d}_{0}-\mathrm{d}_{4}-\mathrm{d}_{2}-\mathrm{d}_{1}-\mathrm{d}_{3}$ \\
\hline U2-I6 & U5-I3 & $a b b$ & $\mathrm{cbb}$ & $a a b$ & $\mathrm{ccb}$ & aaa & $\mathrm{d}_{1}-\mathrm{d}_{3}-\mathrm{d}_{4}-\mathrm{d}_{2}-\mathrm{d}_{0}-\mathrm{d}_{2}-\mathrm{d}_{4}-\mathrm{d}_{3}-\mathrm{d}_{1}$ \\
\hline U3-I1 & U6-I4 & aac & $a a b$ & cac & bab & $\mathrm{ccc}$ & $\mathrm{d}_{1}-\mathrm{d}_{3}-\mathrm{d}_{4}-\mathrm{d}_{2}-\mathrm{d}_{0}-\mathrm{d}_{2}-\mathrm{d}_{4}-\mathrm{d}_{3}-\mathrm{d}_{1}$ \\
\hline U3-I2 & U6-I5 & bbc & aac & $\mathrm{cbc}$ & $\mathrm{cac}$ & bbb & $\mathrm{d}_{3}-\mathrm{d}_{1}-\mathrm{d}_{2}-\mathrm{d}_{4}-\mathrm{d}_{0}-\mathrm{d}_{4}-\mathrm{d}_{2}-\mathrm{d}_{1}-\mathrm{d}_{3}$ \\
\hline U3-I3 & U6-I6 & bba & bbc & aba & $\mathrm{cbc}$ & aaa & $\mathrm{d}_{1}-\mathrm{d}_{3}-\mathrm{d}_{4}-\mathrm{d}_{2}-\mathrm{d}_{0}-\mathrm{d}_{2}-\mathrm{d}_{4}-\mathrm{d}_{3}-\mathrm{d}_{1}$ \\
\hline U3-I4 & U6-I1 & cca & bba & aca & aba & $\mathrm{ccc}$ & $\mathrm{d}_{3}-\mathrm{d}_{1}-\mathrm{d}_{2}-\mathrm{d}_{4}-\mathrm{d}_{0}-\mathrm{d}_{4}-\mathrm{d}_{2}-\mathrm{d}_{1}-\mathrm{d}_{3}$ \\
\hline U4-I5 & U6-I2 & $\mathrm{ccb}$ & cca & bcb & aca & bbb & $\mathrm{d}_{1}-\mathrm{d}_{3}-\mathrm{d}_{4}-\mathrm{d}_{2}-\mathrm{d}_{0}-\mathrm{d}_{2}-\mathrm{d}_{4}-\mathrm{d}_{3}-\mathrm{d}_{1}$ \\
\hline U3-I6 & U6-I3 & $a a b$ & $\mathrm{ccb}$ & $\mathrm{bab}$ & bcb & aaa & $\mathrm{d}_{3}-\mathrm{d}_{1}-\mathrm{d}_{2}-\mathrm{d}_{4}-\mathrm{d}_{0}-\mathrm{d}_{4}-\mathrm{d}_{2}-\mathrm{d}_{1}-\mathrm{d}_{3}$ \\
\hline
\end{tabular}

The working sequence of control pulses for 9 pairs of BDS switches is done according to the following principle.

- If the sum of sectors current with the voltage sector is an even number, the switching sequence in the half-modulation cycle is:

$$
d 1 \rightarrow d 3 \rightarrow d 4 \rightarrow d 2 \rightarrow d 0 \rightarrow d 2 \rightarrow d 4 \rightarrow d 3 \rightarrow d 1
$$

- If the sum of sectors current with the voltage sector is an odd number, the switching sequence in the half-modulation cycle is:

$$
d 3 \rightarrow d 1 \rightarrow d 2 \rightarrow d 4 \rightarrow d 0 \rightarrow d 4 \rightarrow d 2 \rightarrow d 1 \rightarrow d 3
$$

\section{SPEED CONTROLLER}

In this section, two types of controllers were used:

- $\quad$ Open loop V/F control

- $\quad$ Closed Loop V/F Control

\subsection{Open loop V/F control}

$\mathrm{V} / \mathrm{F}$ is the most common speed control of an induction motor. The torque developed by the induction motor is directly proportional to the V/F ratio. The voltage and frequency will change, keeping their ratio constant, then the torque produced by induction motor will remain constant for all the speed range [11]. In addition, V/F is the simplest controller. It assumes a constant relation between voltage and frequency and it is normally used without speed feedback.

The open loop V/F control of an induction motor is the most common method of speed control because of its simplicity and these types of motors are widely used in industry. This type of motor control has these advantages: low cost, simplicity and immunity to errors of feedback signals. Traditionally, induction motors have been used with open loop $50 \mathrm{~Hz}$ power supplies for constant speed applications. For adjustable speed drive applications, frequency control is natural. However, voltage is required to be proportional to frequency so that the stator flux $\psi$ remains constant. Block diagram of the open loop V/F control for an IM as shown in Figure 5. 


\subsection{Closed loop V/F control}

The basis of constant V/F speed control of induction motor is to apply a variable magnitude and variable frequency voltage to the motor as shown in Figure 6. Both the voltage source inverter and current source inverters are used in adjustable speed AC drives. The following block diagram shows the closed loop $\mathrm{V} / \mathrm{F}$ control using a MC.

The closed-loop method offers a more precise solution to controlling the speed than the open-loop method. Furthermore, the closed-loop technique controls the torque too. A major disadvantage of the openloop control method is that this technique does not control the torque, so the desired torque is only accessible at the nominal operating point. If the load torque changes, the speed of the motor will change [11, 12].

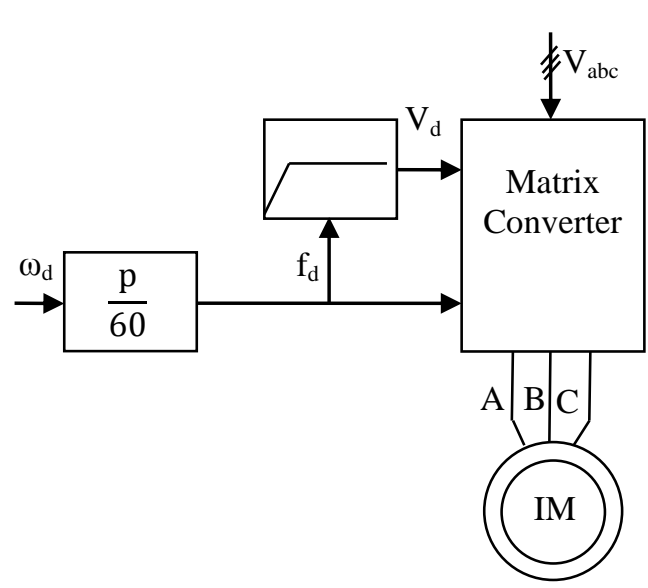

Figure 5. Open loop constant V/F speed control

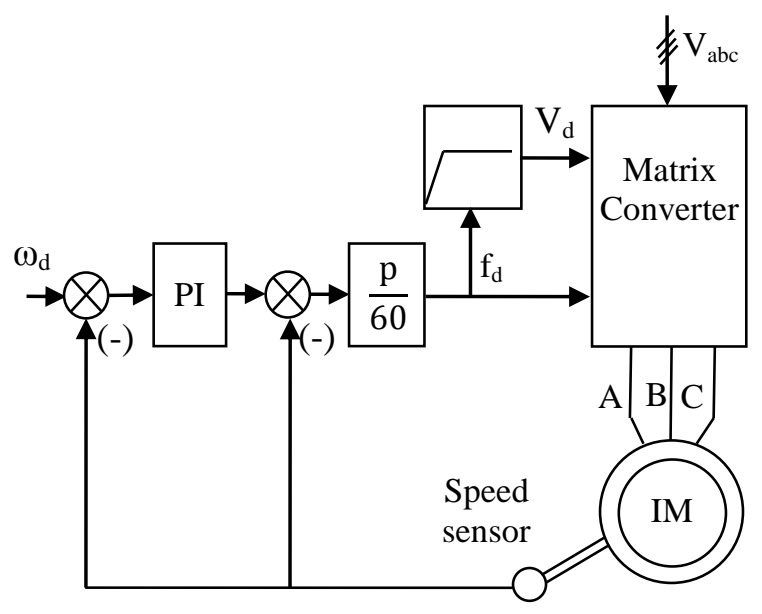

Figure 6. Closed-loop V/Hz constant control

\section{RESULTS AND ANALYSIS}

Use of Matlab \& Simulink software to design switching algorithms for matrix converter.

\subsection{Matrix converter works with load $R, L$}

Input voltage of converter $\mathrm{U}=220 \mathrm{~V}), \mathrm{f}=50(\mathrm{~Hz})$, load $\mathrm{R}=2(\Omega)$ and $\mathrm{L}=10(\mathrm{mH})$, output voltage frequency $\mathrm{fl}=25(\mathrm{~Hz})$. PWM sampling frequency fs $=5(\mathrm{kHz})$. Simulation results from Figure 7 to Figure 11 show that input voltage and current coincide with phase angle, power transmission coefficient $\mathrm{m}=1$, input current is sinusoidal.

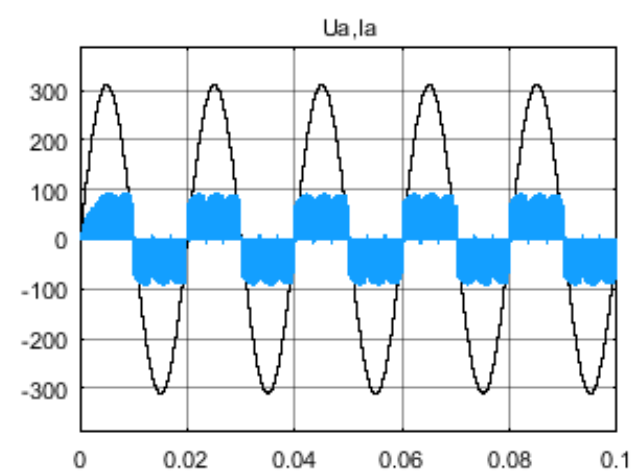

Figure 7 . Voltage and current at the input $(f=50 \mathrm{hz})$

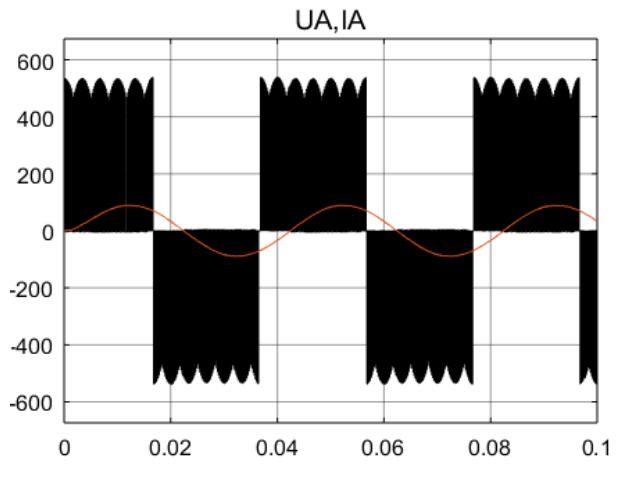

Figure 8 . Voltage and current at the output $(f=25 \mathrm{hz})$ 


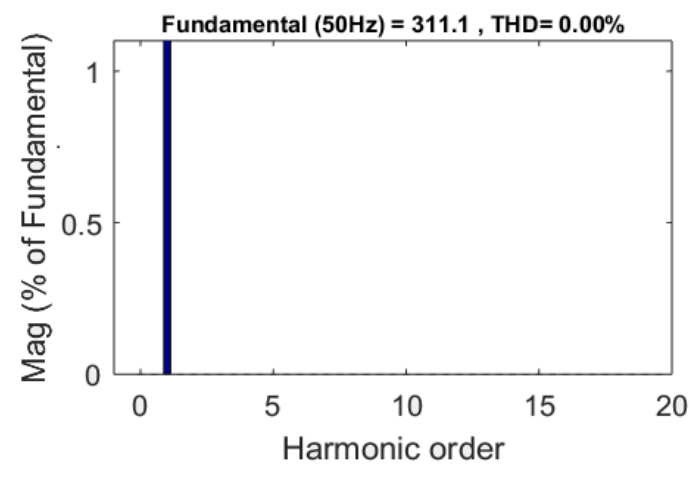

Figure 9. Total harmonic distortion of the input voltage $(\mathrm{THD}=0 \%)$

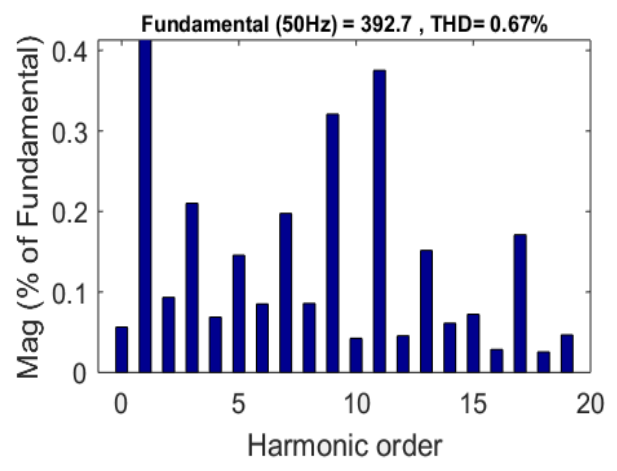

Figure 10. Total harmonic distortion of the output voltage $(\mathrm{THD}=0,67 \%)$

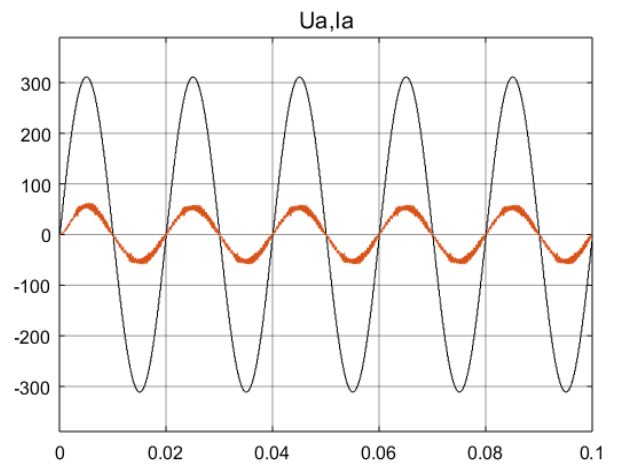

Figure 11. Input voltage and current when using harmonic filter circuit (LC)

\subsection{Application of matrix converter to control $\mathrm{AC}$ motor according to $\mathrm{V} / \mathrm{f}$ rule}

Parameter of induction motor: $\mathrm{P}=1,5(\mathrm{~kW}), \mathrm{U}=220(\mathrm{~V}), \mathrm{f}=50(\mathrm{hz}), \mathrm{Rs}=0,5968(\Omega), \mathrm{n}=1440(\mathrm{rpm})$, $\mathrm{Ls}=0,0003495(\mathrm{H}), \mathrm{J}=0,05(\mathrm{~kg} \cdot \mathrm{m} 2)$.

\subsubsection{Control system has an open loop structure}

When the speed of the motor from 500(rpm) decreases to 200(rpm) at 0.4 seconds, the frequency and input voltage of the motor from $\mathrm{f}=16.67(\mathrm{hz}), \mathrm{V}=83,33(\mathrm{~V})$ decreases to the value $\mathrm{f}=6.667(\mathrm{hz})$ and $\mathrm{V}=33,33(\mathrm{~V})$, always ensure $\mathrm{V} / \mathrm{f}=$ const. Figure 12 shows the diagram of closed loop control system.

\subsubsection{Control system has a closed loop structure}

Regulators for closed loop control circuit with PI structure:

$$
W_{P I}(s)=1,5+\frac{0,8}{s}
$$

Simulation results from Figure 7 to Figure 11 show that input voltage and current coincide with phase angle, power transmission coefficient $\mathrm{m}=1$, input current is sinusoidal. When working with load $\mathrm{R}, \mathrm{L}$, the matrix converter does not cause a total harmonic distortion on the grid voltage $($ THDu $\%=0 \%)$. The voltage and current output on the load are in the sinusoidal form, and has a low harmonic distortion output voltage $(\mathrm{THDu} \%=0.67 \%)$. In particular if the $\mathrm{L}, \mathrm{C}$ harmonic filtering circuit is used at the inverter input, the total harmonic distortion current will decrease significantly.

In open loop control systems as shown in Figure 13 to Figure 15, the speed of the induction motor always follows the setpoint and when the frequency changes, the motor speed changes and always ensures the ratio V/f = const. When the load torque changes, there is a difference between the set speed and the actual speed of the motor. In the closed loop control system as shown in Figure 16 to Figure 18, the output speed clings to the setpoint, when the load torque is available, it always ensures the motor speed follow the setpoint. 


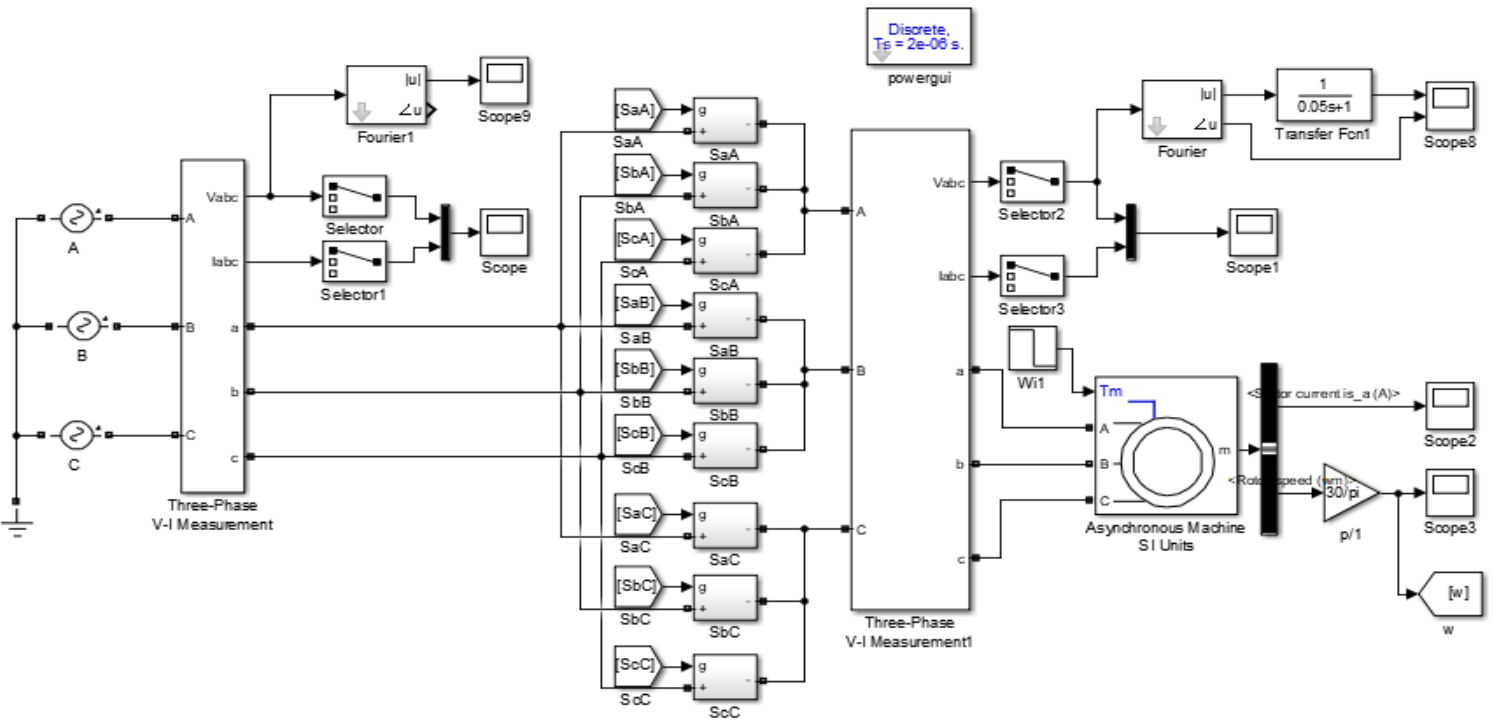

Figure 12. Diagram of closed loop control system

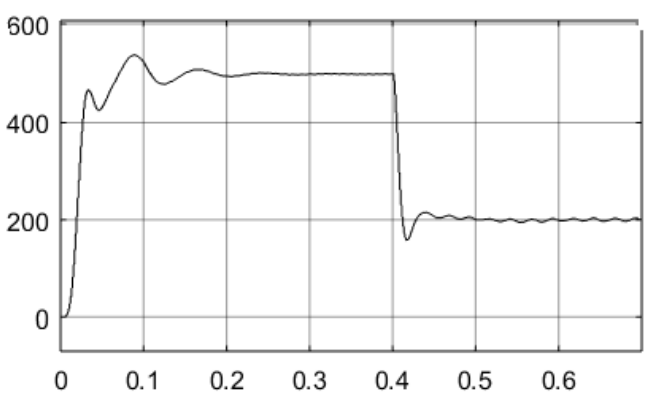

Figure 13. Motor speed without load

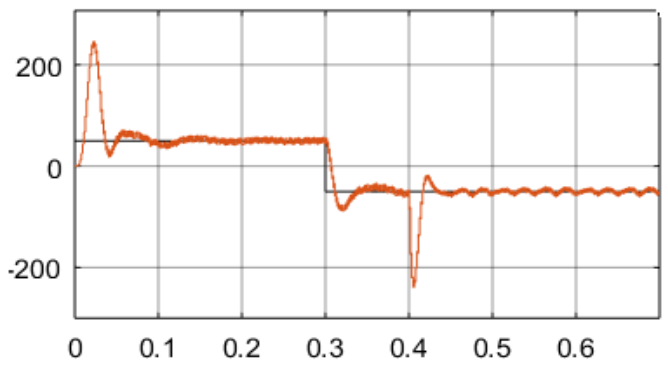

Figure 15. Motor torque and load torque

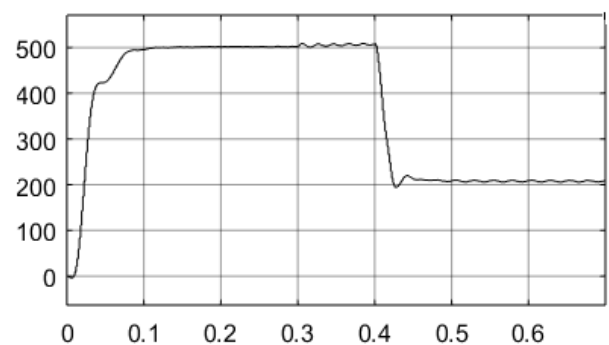

Figure 17. Motor speed with load torque

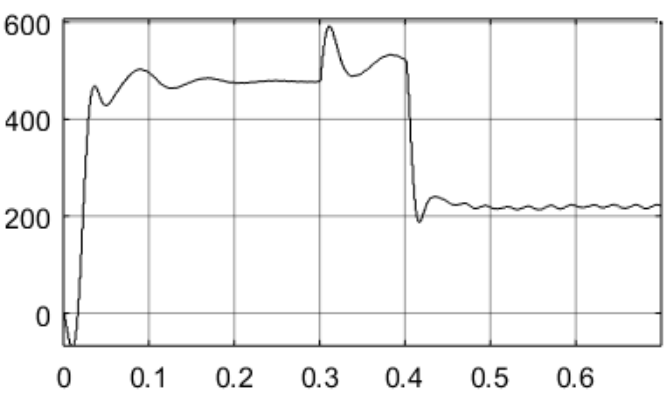

Figure 14. Motor speed with load torque

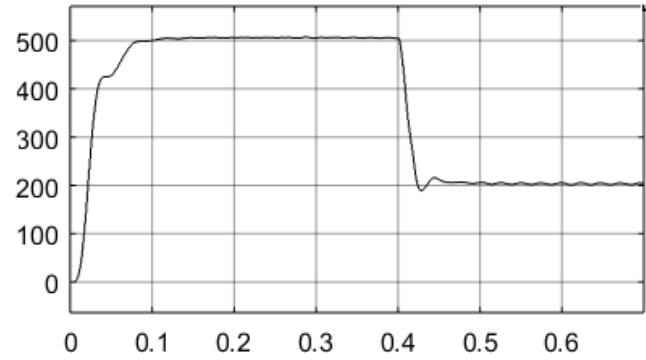

Figure 16. Motor speed without load in closed loop structure

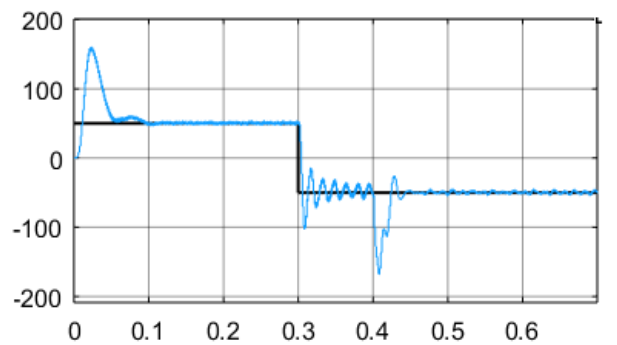

Figure 18. Motor torque and load torque 


\section{CONCLUSION}

The theoretical analysis and the results obtained from the simulation on Matlab show that the matrix converter has more advantages than the present frequency converter in practice. The input current is sinusoidal, the current is almost standard sinusoidal. They can be controlled according to V/f rules like conventional inverters. The matrix converter is a switch matrix, and the switches have a unique $3 \times 3$ format. The method of direct vector space modulation is that in each cycle, it is necessary to determine the phase angle of the input voltage at the time of the source voltage through zero without considering the value of the instantaneous voltage. The output voltage is determined by the required frequency and the desired modulation factor. Thus, there will be a minimum number of steps to calculate the modulation factor, thereby making the anti-jamming ability good.

\section{REFERENCES}

[1] T. Shimizu, K. Kunomura, M. Kai, H. Miyajima and T. Matsui, "Study for further introduction of the Electronic Frequency converters to the Tokaido Shinkansen," 2018 International Power Electronics Conference (IPECNiigata 2018 -ECCE Asia), Niigata, 2018, pp. 1803-1809.

[2] Nabae A, Takahashi I., Akagi H, “A New Neutral Point Clamped PWM Inverter," IEEE Trans. On IA., vol. 17(5), pp. 509- 517, 1981.

[3] Kolar J.W, Baumann M, Schafmeister F, Ertl. H, "Novel three-phase AC-DC-AC sparse matrix converter," Seventeenth Annual, vol. 2, pp. 777 -791, 2002.

[4] H. Karaca and R. Akkaya, "Control of Venturini Method Based Matrix Converter in Input Voltage Variations," in Proceedings of the International Multi Conference of Engineers and Computer Scientists, vol. 2, pp. 1412-1416, 2009.

[5] Satheesh G.; Chamdranth Naidu, Priyanka, P, "Modeling of the matrix converter based on the venturini modulation scheme," IJAICT, vol. 3(11), pp. 1197-1205, 2017.

[6] Bogdan .Y, Le Van Tung, "Research on the Switching Algorithm of Voltage Vectors in the Direct Torque Control System," IEEE Trans. Rus, pp. 80-87, 2018.

[7] Kozaruk A.E, "The experience of creating and redeveloping the development of electromechanical complexestechnological, movement and positioning of technical means for the development of the shelf," Zapiski Gornogo Instituta / Journal of Mining Institute, vol. 221, pp. 701-705, 2016.

[8] Bogdan Yu. Vasilyev, Vadim A. Shpenst, Oleg V. Kalashnikov, Gennadii N. Ulyanov, "Providing Energy Decoupling of Electric Drive and Electric Grids for Industrial Electrical Installations," Zapiski Mining Institute/Journal of Mining Institute, vol. 229(2), pp. 41-49, 2018.

[9] Kozaruk A.E, "Energy-efficient electromechanical complexes of mining and transport vehicles," Zapiski Mining Institute / Journal of Mining Institute, vol. 218. pp. 261-269, 2016.

[10] Larsen K.B, Jorgensen A.H, Helle L, Blaabjerg F, "Analysis of pulse width modulation strategies for matrix converters," IEEE Trans. On Aus, vol. 2, pp 899 -904, 2002.

[11] P.W. Wheeler, J. Rodriguez, J.C. Clare, et al., "Matrix Con-verters: a Technology Review," IEEE Trans. Ind. Electron, vol. 49(2), pp. 276-288, 2002.

[12] Hanan Mikhael D, Hussein Jalil Ajeel, "Speed Control of Induction Motor using PI and V/F Scalar Vector Controllers," International Journal of Computer Applications, vol. 151 (7), 2016, pp. 36-43.

[13] X. Xu, L. Fang, X. Xu and X. Lu, "Control strategy of photovoltaic generation inverter grid-connected operating and harmonic elimination hybrid system," 2017 2nd International Conference on Power and Renewable Energy (ICPRE), Chengdu, 2017, pp. 886-890.

[14] W. Guo, T. Mingxing and R. Enen, "Structure design and its parameter optimization of output filter in current balance compensation inverter for electrified railway," The 2nd International Symposium on Power Electronics for Distributed Generation Systems, Hefei, 2010, pp. 791-795.

[15] H. M. Ahn, W. Sung, M. Kim, B. K. Lee, S. Ryu and C. Lim, "Control method of input-parallel and output-series connected inverters for plasma generator," 2018 IEEE Applied Power Electronics Conference and Exposition (APEC), San Antonio, TX, 2018, pp. 3563-3568.

[16] M. Song, C. Gao, J. Yang and H. Yan, "Energy storage modeling of inverter air conditioning for output optimizing of wind generation in the electricity market," in CSEE Journal of Power and Energy Systems, vol. 4, no. 3, pp. 305-315, Sep 2018.

[17] Xin Li and S. S. Williamson, "Efficiency analysis of hybrid electric vehicle (HEV) traction motor-inverter drive for varied driving load demands," 2008 Twenty-Third Annual IEEE Applied Power Electronics Conference and Exposition, Austin, TX, 2008, pp. 280-285.

[18] V.V. Alekseev, V.I. Vershinin and B.Yu. Vasil'ev, "Definition of parameters of vectors of magnetic flux in electric drives with the vector control," Zapiski Gornogo Instituta/Journal of Mining Institute, vol. 196, pp. 222-225, 2012. 
[19] A. Anuchin, D. Shpak, A. Zharkov, V. Ostrirov and Y. Vagapov, "A method of determining the maximum performance torque-speed characteristic for an induction motor drive over its entire speed range," 2017 IEEE 58th International Scientific Conference on Power and Electrical Engineering of Riga Technical University (RTUCON), Riga, 2017, pp. 1-5.

[20] G. Yang, M. Lin, G. Tan and H. Li, "Direct Input Power Control for Drive System of Single-Phase to Three-Phase Power Converter Without Electrolytic Capacitor," 2018 21st International Conference on Electrical Machines and Systems (ICEMS), Jeju, 2018, pp. 1503-1507.

[21] Zhongyuan Zhao, Zhengyu Lu, Gaoxian Jin, Wanmen Fei and Linghui Xia, "Development of gate-driving system of thyristor valve with multiple isolated outputs used in new-type solid-state short-circuit fault current limiter in electric power system," 2004 IEEE 35th Annual Power Electronics Specialists Conference (IEEE Cat. No.04CH37551), Aachen, Germany, 2004, pp. 3233-3236.

[22] B. Yu.Vasil'ev, V. A. Shpenst, O. V. Kalashnikov, and G. N. Ul'yanov, "Providing energy decoupling of electric drive and electric grids for industrial electrical installations, " Zapiski Gornogo Instituta / Journal of Mining Institute, vol. 229, pp. 41-49, 2018.

[23] V. Ansal, P. Parthiban and K. Ravikumar, "Performance study of high frequency link AC-AC converter," 2014 International Conference on Advances in Energy Conversion Technologies (ICAECT), Manipal, 2014, pp. 164-168.

[24] P. Szczesniak, "Basic Properties Comparative Study of Matrix-Reactance Frequency Converter Based on Buck-Boost Topology with Venturini Control Strategies," 2007 Compatibility in Power Electronics, Gdansk, 2007, pp. 1-7.

[25] W. Fa-Qiang, M. Xi-Kui and Y. Ye, "Low frequency oscillation in the PI type of average current controlled Boost converter," 2011 International Conference on Electronics, Communications and Control (ICECC), Ningbo, 2011, pp. 3792-3795.

\section{BIOGRAPHIES OF AUTHORS}

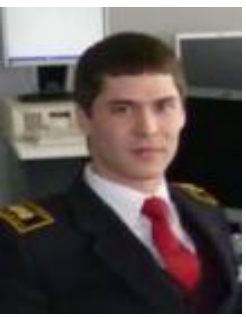

Bogdan Vasilev Graduated from Uchtincskiy technical university in 2010. Received P.H.D degree in National Mineral Resources University in 2013. He is assistant professor in electrical energy and electromechanics department since 2013. His research interest includes electromagnetic compatibility providing, electrotechnical systems for energy industry.

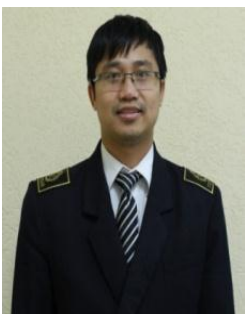

Le Van Tung Receive a master's degree at Thai Nguyen University of Technology, Viet Nam in 2013. Graduate student at Saint-Petersburg Mining University, Russia Federation. His research interest includes electromagnetic compatibility providing, electrotechnical systems for energy industry. 